\title{
Actividad antibacteriana y antioxidante de Baccharis revoluta Kunth
}

\author{
Antibacterial and Antioxidant Activity of Baccharis revoluta Kunth
}

Óscar E. Rodríguez A ${ }^{1}$, Virginia P. Roa A ${ }^{1}$,Édgar A. Palacios $\mathbf{O}^{1}$

\section{Resumen}

Objetivo: Evaluar la actividad antibacteriana y antioxidante de las partes aéreas de Baccharis revoluta. Métodos: La especie fue colectada en el municipio de Chocontá, Cundinamarca (N 05 08’ 26,3” W $73^{\circ} 38$ ' 59,2”). A los extractos de hojas, tallos y flores de diferente polaridad se les determinó la actividad antibacteriana frente a los microorganismos Staphylococcus aureus Gram (+), Klebsiella pneumoniae Gram (-) y Escherichia coli Gram (-), utilizando el método de difusión en gel por perforación en placa y se le evaluó la actividad antioxidante por el método DPPH•. Resultados: Las pruebas de eficacia antimicrobiana exhibieron inhibición significativa de los extractos. Además, se determinó la concentración crítica, que representa una medida de la susceptibilidad del microorganismo, y los extractos presentaron mayor actividad antibacteriana frente a Staphylococcus aureus que a Klebsiella pneumoniae y Escherichia coli. Los extractos etanólicos presentaron una actividad antioxidante representativa, con una $\mathrm{IC}_{50} \mathrm{y}$ actividad antioxidante relativa de 7,2\% y 43.64\%, para el extracto etanólico de hojas, 6,95\% y $45.57 \%$ para el extracto etanólico de tallos y 7,1\% y 44.16 \% para el extracto etanólico de flores, lo que nos determina una gran potencialidad de estos extractos etanólicos.

Palabras Clave: Baccharis revoluta Kunth, actividad antibacteriana, actividad antioxidante.

\section{Abstract}

Objective. To vvaluate the antibacterial and antioxidant activity of the aerial parts of Baccharis revolute. Methods. The species was collected in the municipality of Chocontá, Cundinamarca (N $05^{\circ} 08$ '26.3 “W $73^{\circ} 38^{\prime}$ '59.2”). In extracts of leaves, stems and flowers of different polarity were determined in antibacterial activity against the microorganisms Staphylococcus aureus Gram (+), Klebsiella pneumoniae Gram (-) and Escherichia coli Gram (-) using the gel diffusion method by drilling plate and he evaluated the antioxidant activity by the DPPH • method. Results. Antimicrobial efficacy tests showed significant inhibition of the extracts. Moreover, the critical concentration, which is a measure of the susceptibility of the microorganism was determined, and the extracts showed greater antibacterial activity against Staphylococcus aureus than Klebsiella pneumoniae and Escherichia coli. Ethanolic extracts showed a representative antioxidant activity, an antioxidant activity IC50 and on 7.2\% and 43.64\% for the ethanol extract of leaves, 6.95 and $45.57 \%$ for the ethanol extract of stems and $7.1 \%$ and $44.16 \%$ for the ethanol extract of flowers wich determines us great potential of these ethanolic extracts.

Key Words: Baccharis revoluta Kunth, antibacterial activity, antioxidant activity. 


\section{Introducción}

En Colombia existe diversidad de especies vegetales, entre las que se encuentran las pertenecientes al género Baccharis (1-4). Muchas reportan uso popular medicinal y agrario. Del género se han estudiado varias especies y se han observado compuestos de tipo: sesquiterpenos, triterpenos, flavonoides, flavanonoles, ácidos grasos cíclicos, lactonas sesquiterpénicas, diterpenos, ent-clerodanos, prostaglandinas provenientes de ácidos grasos libres y chalconas metiladas (5-13). Asimismo, se han realizado estudios sobre su actividad biológica, como: pesticida, repelente, efecto antiprotozoario, insecticida, tripanozoica, antibacterial, antimicobacterial, citotoxicidad, efectos antioxidantes y mutagenicidad.

Estudios como los de Thais et al (14), reportan que Baccharis trimera presenta componentes que inhiben la secreción gástrica, actuando principalmente en la vía de reglamentación colinérgica, determinando que el extracto de la planta contiene compuestos que ejercen una inhibición moderada de la vía de regulación de la secreción ácida y la bomba de protones gástrica. También verificaron que los componentes activos proporcionan una eficaz inhibición de la secreción de ácido en vivo, lo que podría explicar la actividad antiulcerosa. Rodrígues et al (15) reportan en Baccharis dracunculifolia (DC) (Asteraceae) planta nativa de Brasil, conocida como "vassourinha" o "Alecrim-do-campo", que los extractos de las hojas son utilizados para tratar trastornos de hígado y del aparato digestivo.

Da Cruz et al (16) refieren que el extracto hidroetanólico de Baccharis trimera reduce la liberación de especies reactivas del oxígeno en los neutrófilos, in vitro y en modelos experimentales in vivo, y confirman su efecto antioxidante. Xavier et al (17-18) informan que Baccharis uncinella DC, Baccharis anomala DC y Baccharis dentata GM (Vell) presentan un alto potencial aromático de los aceites esenciales obtenidos por el método de destilación de vapor. El análisis del aceite esencial se llevó a cabo por GC-MS y los principales compuestos identificados para ambos procesos fueron $\alpha$-pineno, $\beta$-pineno y spathulenol $(B$. uncinella), spathulenol, $\beta$-cariofileno, y $\beta$-selineno ( $B$. anomala), y germacreno $\mathrm{D}$-, óxido de cariofileno y spathulenol (B. dentata). Egly et al (18) reportan que en Argentina el exudado resinoso de Baccharis grisebachii se utiliza para tratar úlceras, quemaduras y llagas en la piel, y mostró actividad a dermatofitos y bacterias. Además, identificaron dos diterpenos, ocho derivados del ácido p-cumárico y dos flavonas el 3-prenil-p-cumárico y el ácido 3,5-diprenil-p-cumárico. Es activo a Epidermophyton floccosum y Trichophyton rubrum con CMI de 50 y 100 a 125 mg/ml, respectivamente.

El diterpeno Labda-7,13E-dien-2 $\beta, 15-d i o l$ es activo a Epidermophyton floccosum y Trichophyton rubrum con CMI de $12.5 \mathrm{mg} / \mathrm{ml}$, mientras que la CMI contra el Microsporum canis y Trichophyton mentagrophytes fue de $25 \mathrm{mg} / \mathrm{ml}$. El diterpeno fue también activo hacia Microsporum gypseum con una CMI de 50 $\mathrm{mg} / \mathrm{ml}$, y mostró una inhibición en Staphylococcus aureus (cepas de $S$. aureus meticilina resistente y sensible) con una CMI de $125 \mathrm{mg} / \mathrm{ml}$. Los resultados apoyan el uso de Baccharis grisebachii en la medicina tradicional. A la especie Baccharis revoluta (romerillo), que se localiza en la región cundiboyacense, especie que solo se ha encontrado en Colombia y que no presenta estudios químicos ni biológicos se le evaluó la actividad antibacteriana por la técnica de perforación en placa con la finalidad de encontrar nuevas alternativas terapéuticas efectivas contra las infecciones producidas por microorganismos resistentes a los antibióticos. En tal sentido, se buscaron fracciones potenciales con efecto antibacteriano de las partes aéreas de la especie. Además se evaluó la actividad antioxidante.

\section{Materiales y métodos}

\section{Procedencia del material botánico}

Se colectó $1 \mathrm{~kg}$ de muestra sana y florecida en el municipio de Chocontá, Cundinamarca ( $\mathrm{N} 05^{\circ} 08^{\prime}$ 26,3” W $\left.73^{\circ} 38^{\prime} 59.2^{\prime \prime}\right)$. Un ejemplar se preparó 
para la identificación taxonómica en el Herbario Nacional Colombiano del Instituto Nacional de Ciencias Naturales de la Universidad Nacional de Colombia, determinada por el doctor José Aguilar Cano como Baccharis revoluta Kunth y registrada con el código: COL 566217.

\section{Obtención de los extractos y fracciones}

Las partes aéreas (hojas, tallos y flores) se secaron a la sombra y se molieron hasta un tamaño de partícula adecuado para la extracción. Se utilizó el equipo de extracción Soxhlet, que permite mantener la identidad química original o natural de los principios activos de la planta. Las extracciones se realizaron con solventes de polaridad ascendente: éter de petróleo, diclorometano, acetona, metanol y extracción total con etanol agua (19) los cuales se fraccionaron.

\section{Actividad antimicrobiana}

Los microorganismos utilizados para la determinación de actividad antibacteriana en este estudio proceden de las denominadas cepas de control, de acuerdo a la clasificación de la American Type Culture Collection (ATCC). Para bacterias Gram positivas se utilizó como microorganismo indicador Staphylococcus aureus ATCC \# 25923 mientras que para Gram negativas se utilizó como microorganismos indicador Escherichia coli ATCC 13706 y Klebsiella pneumoniae ATCC \# 70063.

Se empleó el método de difusión en gel por perforación en placa, usando como medio de crecimiento bacteriano el agar Müeller Hinton, debido a su buena reproducibilidad para el crecimiento de la mayoría de bacterias. Es un medio simple, transparente y sin materiales termolábiles, además contiene almidón, que contribuye al fomento del crecimiento (20-21).

\section{Preparación de soluciones}

Preparación de patrones. Se tomaron $10 \mathrm{mg}$ de antibióticos: moxifloxacina $400 \mathrm{mg}$, cefalexina $500 \mathrm{mg}$, amoxicilina $500 \mathrm{mg}$, ciprofloxacino 1000 $\mathrm{mg}$, rifaximina en $200 \mathrm{mg}$ en $10 \mathrm{ml}$ de DMSO, y se diluyo con un factor de $1 / 2$.

Preparación de extractos de diferente polaridad de Baccharis revoluta. Se preparó una solución stock 1000 ppm de cada extracto a evaluar disolviendo $10 \mathrm{mg}$ en $10 \mathrm{ml}$ de DMSO.

Preparación de los medios de cultivo. Se tomaron $34 \mathrm{~g}$ de Muller Hilton por litro de agua según indicación del producto y se prepararon cajas con $30 \mathrm{ml}$ de agar estéril. Se realizaron cuatro perforaciones y se sellaron las bases con $15 \mathrm{ml}$ de agar. En cajas Petri con $25 \mathrm{ml}$ de Agar Muelle-Hinton se realizaron las siembras de $0.1 \mathrm{ml}$ de los inóculos preparados para cada patógeno correspondiente a la concentración 0.5 de la escala de McFarland, $\left(1.5 \times 10^{8} \mathrm{UFC} / \mathrm{ml}\right)$, utilizando la siembra masiva.

Posteriormente se realizaron 4 perforaciones equidistantes de $8 \mathrm{~mm}$ a las cuales se les sellaron el fondo con AMH. Sellados los fondos se agregaron las muestras para análisis, evaluándose 4 concentraciones de extractos. Para ello se tomó $100 \mathrm{mg}$ de extracto seco y se diluyó en $1 \mathrm{ml}$ de DMSO, obteniéndose una dilución principal de la cual se tomaron: $(10 \mu \mathrm{l})$ correspondiente $1 \mathrm{mg}$, de extracto $(20 \mu \mathrm{g} / \mu \mathrm{l}),(20 \mu \mathrm{l})$ correspondiente a $2 \mathrm{mg}(40 \mu \mathrm{g} / \mu \mathrm{l}),(30 \mu \mathrm{l})$ correspondiente a $3 \mathrm{mg},(60$ $\mu \mathrm{g} / \mu \mathrm{l})$ y $(50 \mu \mathrm{l})$, correspondiente a $5 \mathrm{mg},(100 \mu \mathrm{g} / \mu \mathrm{l})$ y para los patrones se tomó $10 \mathrm{mg}$ de patrón Rifaximina y se diluyeron en $10 \mathrm{ml}$ de DMSO, a la dilución principal se le realizó un factor de dilución de $1 / 2$ de la que se tomaron $(10 \mu \mathrm{l})$ correspondiente $0,005 \mathrm{mg}$ de patrón, $(0,1 \mu \mathrm{g} / \mu \mathrm{l}),(20 \mu \mathrm{l})$ correspondiente $0,01 \mathrm{mg}$, $(0,2 \mu \mathrm{g} / \mu \mathrm{l}),(30 \mu \mathrm{l})$ correspondiente $0,015 \mathrm{mg}(0,3 \mu \mathrm{g} /$ $\mu \mathrm{l})$ y $(50 \mu \mathrm{l})$ correspondiente $0,025 \mathrm{mg}(0,5 \mu \mathrm{g} / \mu \mathrm{l})$. La observación de las respuestas antimicrobianas en estas cantidades de extracto permitió observar una correlación entre la concentración de extracto y la acción antimicrobiana, es decir, se puede apreciar si hay una correcta difusión de las sustancias en el agar.

Una vez aplicadas las muestras se dejaron en predifusión durante 30 minutos a temperatura ambiente, se incubaron a $37^{\circ} \mathrm{C}$ y se realizaron las medidas de los diámetros de inhibición a las 24 
horas. Luego se graficó el logaritmo natural (Ln) de las masas de los extractos empleadas contra el cuadrado de los diámetros de inhibición $\left(\mathrm{X}^{2}\right)$; de esta forma se obtiene una recta que se ajusta por mínimos cuadrados y por extrapolación se halla el punto de intersección sobre la ordenada que corresponde al valor de la concentración crítica (C.C.) en mg. La concentración crítica se define como la concentración de la sustancia antimicrobial que se difunde en la superficie del agar o gel, en la interface entre bacterias en crecimiento y bacterias inhibidas; representa una medida de la susceptibilidad de un microorganismo prueba, este valor se aproxima a la CMI obtenida en las pruebas de dilución. Se determinó la actividad antibacteriana relativa (ABR), con respecto a la Rifaximina que es equivalente a $\left(\mathrm{C}_{50}\right.$ muestra / $\mathrm{C}_{50}$ rifaximina $\left.) \times 100\right)$

En la actividad antibacteriana relativa $\{\ln A B R=$ (ln C50 patrón de referencia)/ (ln C50 muestra analizada analizada) X 100\}, se muestra el porcentaje de actividad de los extractos analizados con respecto al patrón usado y representa una medida de la susceptibilidad del microorganismo.

\section{Actividad antioxidante}

El radical $\mathrm{DPPH} \bullet$ es un radical nitrogenado orgánico y estable, posee un intenso color púrpura y se encuentra en forma de radical, no necesita generación previa. El método fue planteado por Brand-Williams en 1995 (22), donde la capacidad antioxidante se basa en la disminución de color, medido a $517 \mathrm{~nm}$, por acción de un compuesto antioxidante; igualmente, dicha actividad puede ser medida por resonancia espín-electrón (23). A género baccharis se le han realizado varios estudios de actividad antioxidante (16, 24-25).

\section{Preparación de soluciones}

Preparación del radical DPPH•: se disolvieron $2 \mathrm{mg}$ de DPPH• Sigma-Aldrich, en $100 \mathrm{ml}$ de metanol. La solución se dejó reaccionar a temperatura ambiente durante 30 minutos en la oscuridad.
Posteriormente fueron preparadas soluciones de trabajo hasta obtener una absorbancia de $0.800 \pm$ 0.050 para todos los casos (26-30) a una longitud de onda de $517 \mathrm{~nm}$.

Preparación de extractos de diferente polaridad de Baccharis revoluta: se preparó una solución stock 1000 ppm disolviendo $10 \mathrm{mg}$ de extracto en 10 $\mathrm{mL}$ de metanol, luego se prepararon diluciones con rangos de concentración entre 500, 100, 10 y 1 ppm.

Preparación de vitamina $C$ : se preparó una solución stock $1000 \mathrm{ppm}$ disolviendo $10 \mathrm{mg}$ de ácido ascórbico en $10 \mathrm{~mL}$ de metanol, luego se prepararon diluciones con rangos de concentración entre 500,100,10,1 y 0,1ppm con el fin de realizar la curva de referencia.

Preparación de la curva de referencia: a $900 \mu \mathrm{L}$ del radical $\mathrm{DPPH} \bullet$ se le adicionaron $300 \mu \mathrm{L}$ de cada una de las diluciones de ácido ascórbico, la medición se realizó a $517 \mathrm{~nm}$, y el porcentaje de captación se calculó con base en la siguiente ecuación:

$\%$ de Captación DPPH = (A “inicial" - A final $) /(\mathrm{A}$ inicial) $x 100$. El porcentaje de captación representa la pérdida del color purpura a amarillo del radical $\mathrm{DPPH}$, cuando le es agregado un compuesto antioxidante, disminuyendo así la absorbancia de la solución, que es medida a $517 \mathrm{~nm}$; la absorbancia inicial se toma en el minuto cero sin adición del antioxidante referencia (ácido ascórbico), la absorbancia final se toma 10 minutos después de agregar el antioxidante de referencia.

Medición de la actividad antioxidante de los extractos de Baccharis revolutum: en una cubeta de plástico con volumen reducido se agregó $900 \mu \mathrm{L}$ del radical DPPH•, se midió la absorbancia a $517 \mathrm{~nm}$, luego se adicionaron $300 \mu \mathrm{L}$ del extracto y fracciones a evaluar y nuevamente se midió la absorbancia cada 30 segundos hasta completar 10 minutos; con los datos obtenidos se determinó el Coeficiente de Inhibición media $\left(\mathrm{IC}_{50}\right)$, que se calcula con la ecuación de la recta obtenida. Para calcular el $\mathrm{IC}_{50}$ se 
sustituye (y) por 50, y así calculamos el porcentaje de captación de $\mathrm{DPPH} \bullet(22)$.

\section{Actividad antioxidante relativa}

La Actividad Antioxidante Relativa AAR $=\left(1 / \mathrm{IC}_{50}\right.$ muestra de referencia) / ( $1 / \mathrm{IC}_{50}$ patrón analizada $) \mathrm{x}$ 100, muestra el comportamiento de las fracciones analizadas comparadas con el patrón usado.

\section{Resultados}

La actividad antibacteriana y antioxidante se evaluaron por los métodos antes descritos y sus resultados los presentamos en las figuras siguientes: La figura 1 muestra la concentración critica $\left(\mathrm{C}_{50}\right)$ evaluada a las bacterias Klebsiella pneumoniae, Escherichia coli y Staphylococcus aureus, frente a los extractos y fracciones de diferentes órganos de Baccharis revoluta.

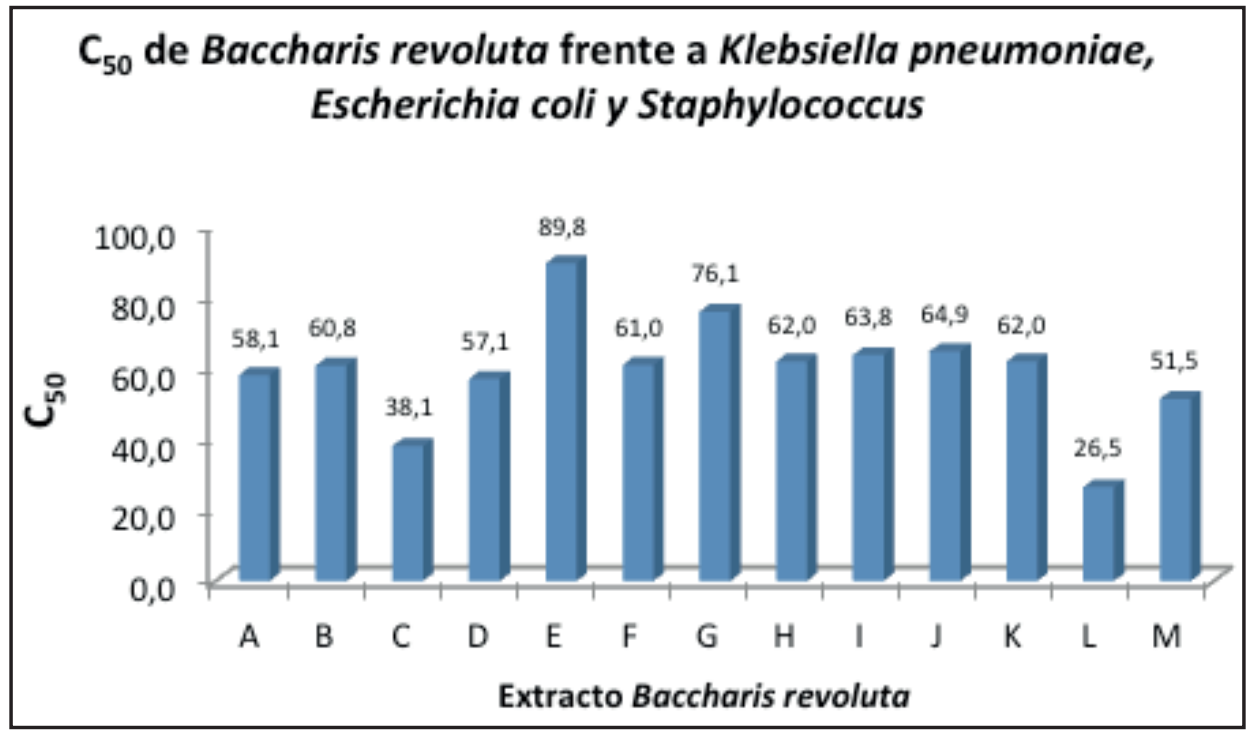

Figura 1. $\mathrm{C}_{50}$ de extractos de Baccharis revoluta Klebsiella pneumoniae [t. petrol (A), t. dicloro (B) ], Escherichia coli [t. petrol (C), t. dicloro (D), f. acetona (E) ], Staphylococcus aureus [h. petrol (F), h. dicloro $(\mathrm{G})$, h. metanol $(\mathrm{H})$, t. petrol (I), t. dicloro $(\mathrm{J})$, t. metanol (K), f. acetona (L), f.metanol (M)].

La Figura 2 muestra la actividad antibacteriana relativa (ABR), evaluada a las bacterias Klebsiella pneumoniae, Escherichia coli y Staphylococcus aureus frente a los extractos y fracciones de diferentes órganos de Baccharis revoluta.con respecto a la rifaximina.

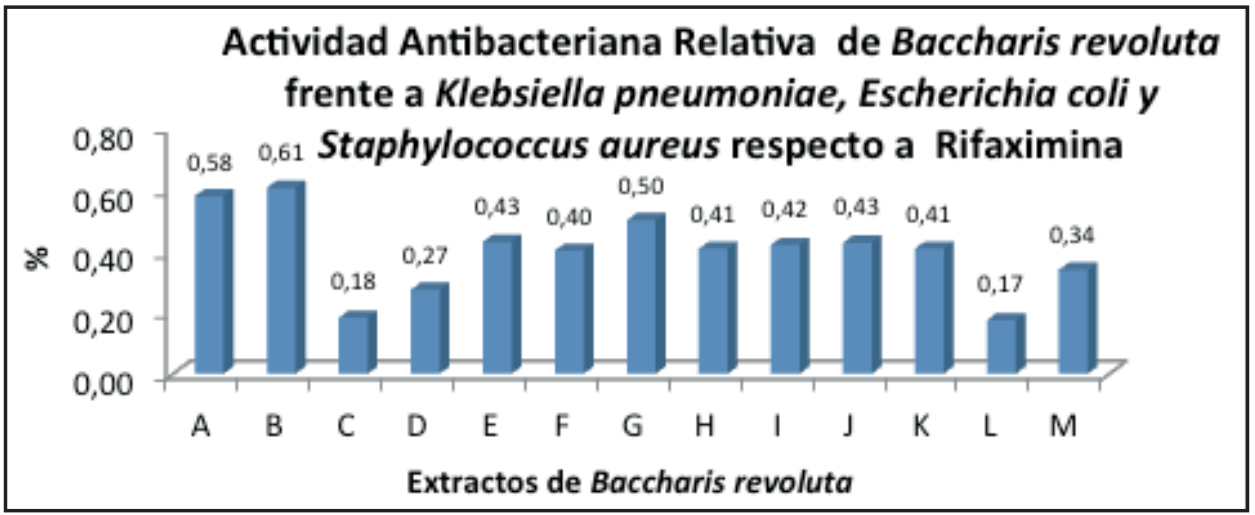

Figura 2. ABR de extractos de Baccharis revoluta frente a rifaximina: Klebsiella pneumoniae [t. petrol (A), t. dicloro (B) ], Escherichia coli [t. petrol (C), t. dicloro (D), f. acetona (E) ], Staphylococcus aureus [h. petrol (F), h. dicloro $(\mathrm{G})$, h. metanol $(\mathrm{H})$, t. petrol (I), t. dicloro (J), t. metanol (K), f. acetona (L), f. metanol (M)]. 
La Figura 3 muestra la cinética de los extractos etanólicos de Baccharis revoluta evaluados por la técnica $\mathrm{DPPH} \bullet$ en comparación con el ácido ascórbico.

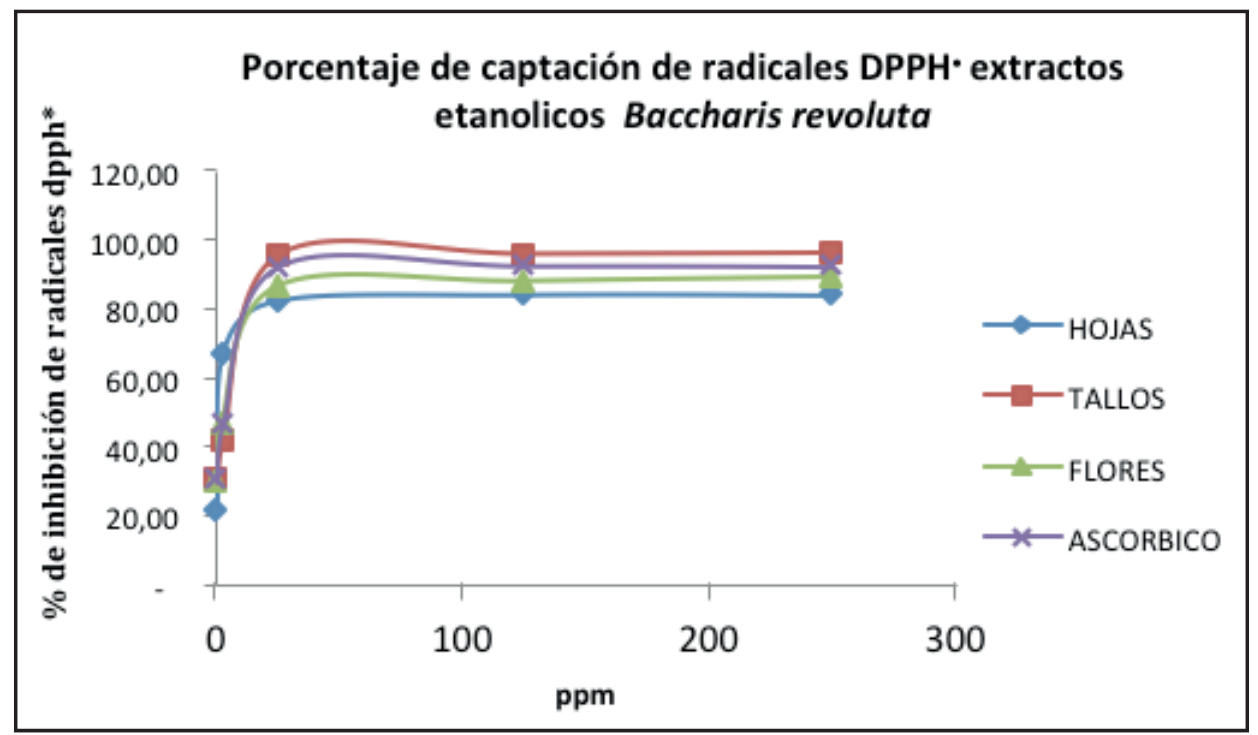

Figura 3. Porcentaje de captación DPPH• de extractos etanólicos de Baccharis revoluta.

La Figura 4 muestra capacidad antioxidante 50 $\left(\mathrm{IC}_{50}\right)$ evaluada a los extractos y fracciones de diferentes órganos de Baccharis revoluta.por el método DPPH•.

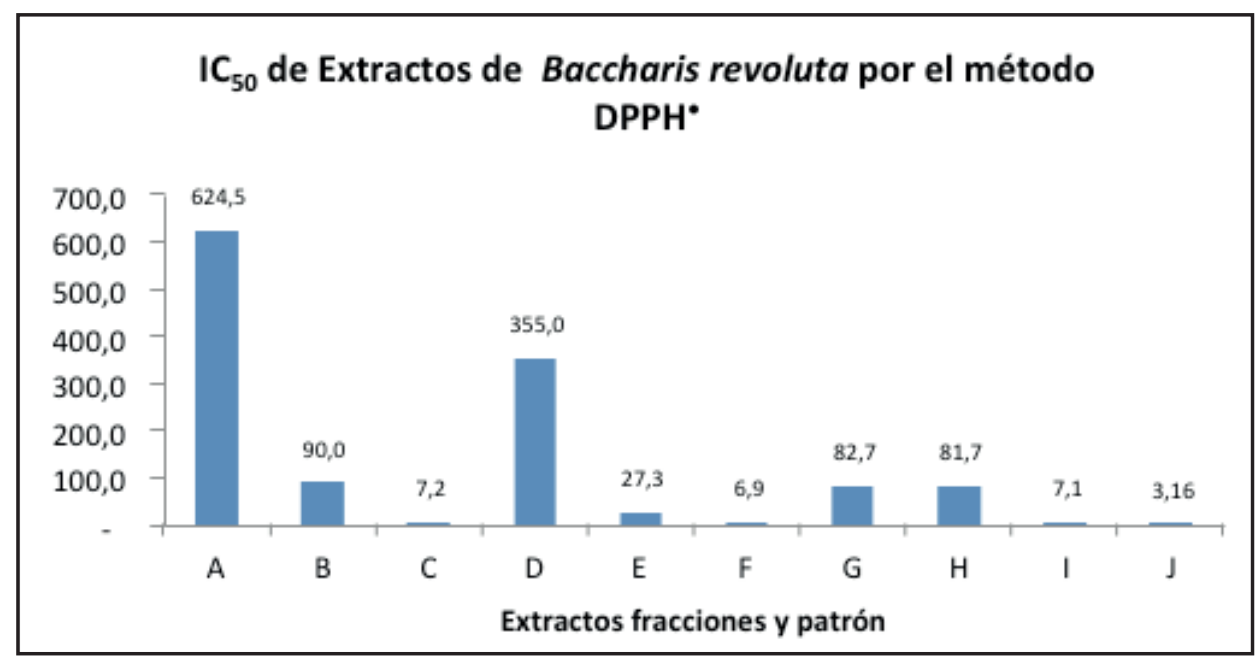

Figura 4. $\mathrm{IC}_{50}$ de extractos de Baccharis revoluta por el método DPPH • hojas [petrol (A), diclorometano (B), etanólico (C)], tallos [petrol (D), diclorometano (E), etanólico (F), diclorometano fracción acetona $(\mathrm{G})$ ], flores [diclorometano $(\mathrm{H})$, etanólico $(\mathrm{I})$ ]. àcido ascórbico $(\mathrm{J})$. 
La Figura 5 muestra la actividad antioxidante relativa (AAR) evaluada a los extractos y fracciones de diferentes órganos de Baccharis revoluta por el método DPPH•.

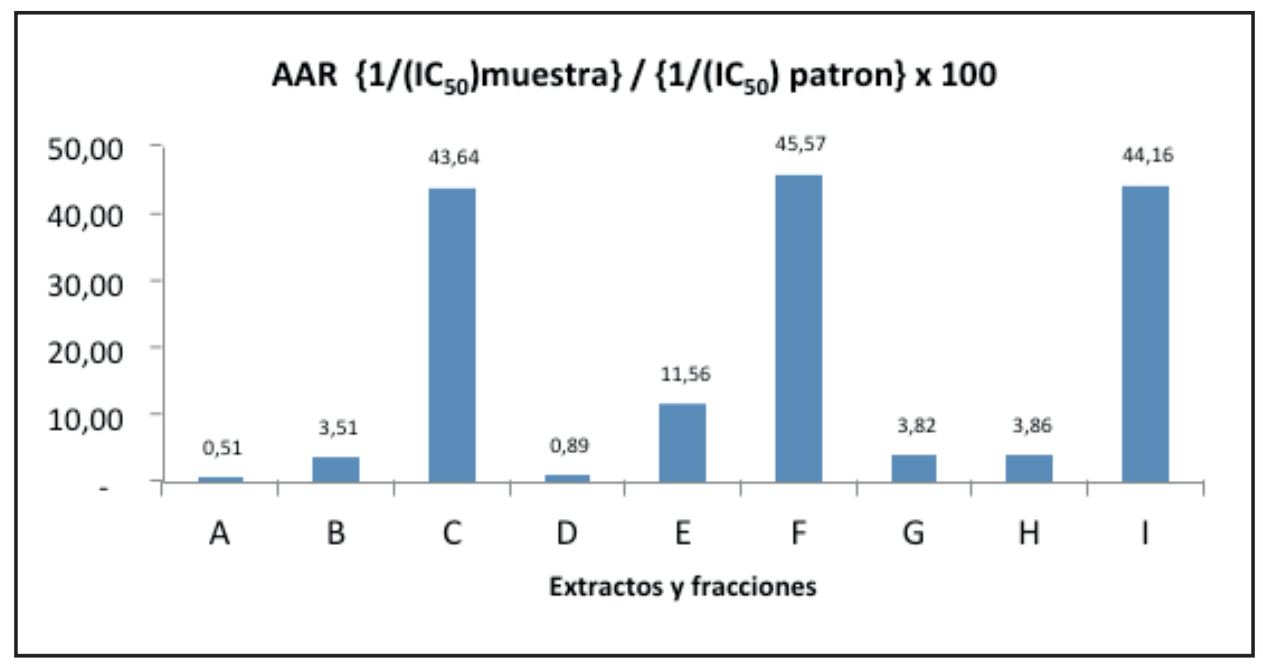

Figura 5. AAR de extractos y fracciones de Baccharis revoluta por el método DPPH・ respecto al ácido ascórbico hojas [petrol (A), diclorometano (B), etanólico (C)], tallos [petrol (D), diclorometano (E), etanólico $(\mathrm{F})$, diclorometano fracción acetona $(\mathrm{G})$ ], flores [diclorometano $(\mathrm{H})$, etanólico $(\mathrm{I})$ ].

\section{Discusión}

Actividad antibacteriana. Las pruebas de eficacia antibacteriana exhibieron inhibición significativa de los extractos. Se determinó la concentración crítica, el Ln de la actividad antibacteriana relativa (Ln ABR) y la actividad anti antibacteriana relativa (ABR) con respecto a la Rifaximina que representa una medida de la susceptibilidad del microorganismo. El Ln de actividad antibacteriana relativa (ln $A B R$ ) se calculó con la $\operatorname{LnAMR}=$ (Ln $\mathrm{C}_{50}$ patrón de referencia) / ( $\mathrm{Ln} \mathrm{C}_{50}$ muestra analizada analizada) x 100 .

Al realizar las pruebas de susceptibilidad antibacteriana con los extractos de hojas, tallos y flores pudo determinarse mediante el método de difusión en gel, que la mayoría de extractos presentaron actividad frente a Staphylococcus aureus. Solo los extractos tallos petrol, tallos diclorometano y flores acetona presentaron actividad frente a Escherichia coli y Klebsiella pneumoniae. Se evidenció la presencia de halo de inhibición o disminución del crecimiento bacteriano en las diferentes concen- traciones empleadas frente al grupo de bacterias (Figura 1). Así mismo, siguiendo la metodología descrita, se determinó la masa crítica (MC) de los extractos frente a los microorganismos de ensayo que representa la masa mínima de extracto para inhibir el desarrollo del microorganismo in vitro en las condiciones empleadas. Así se demuestra que cuando las condiciones son estandarizadas se cumple que el diámetro del halo alrededor del antimicrobiano es proporcional al Ln de la concentración del mismo. Por los resultados expuestos anteriormente se observa que al estar los extractos de hojas, tallos y flores constituidos por variedad de sustancias en diferentes proporciones y características, no es posible comparar la "potencia” con respecto al patrón.

De este estudio se puede concluir que los extractos de la especie Baccharis revoluta presentan actividad antibacterial, frente a los microorganismos Staphylococcus aureus Gram (+), Klebsiella pneumoniae Gram (-) y Escherichia coli Gram (-), mediante el método de difusión en gel por perforación en placas. Los extractos de tallos (petrol) y tallos (di- 
cloro) presentaron actividad antibacteriana frente a Klebsiella pneumoniae con una actividad antibacteriana relativa $(\mathrm{ABR})$ con respecto a la rifaximina de 0.58 y 0.61 respectivamente. Los extractos de tallos (extracto petrol y diclorometano) y flores acetona presentaron actividad antibacteriana frente a Escherichia coli con una actividad antibacteriana relativa (ABR) con respecto a la rifaximina de 0.18 , 0.27 y 0.43 respectivamente. Los extractos de hojas (extractos petrol, dicloro y metanol), tallos (extractos petrol, dicloro y de metanol), flores (extracto acetona y metanol) presentaron actividad antibacteriana frente a Staphylococcus aureus con una actividad antibacteriana relativa (ABR) con respecto a la rifaximina de $0.40,0.50,0.41,0.42$, $0.43,0.41,0.17$ y 0.34 respectivamente.

Actividad antioxidante. El método se utilizó para la evaluación de extractos y fracciones de diferentes polaridades de hojas, y flores; las concentraciones evaluadas fueron $250,125,25,2,5$ y $0,25 \mathrm{ppm}$. El porcentaje de captación de radicales por el método $\mathrm{DPPH} \bullet$ se encontró en un rango de $22.052 \pm$ 0.101 y $96.000 \pm 0.432$ a $250 \mathrm{ppm}$; el coeficiente de captación $\left(\mathrm{IC}_{50}\right)$ y la actividad antioxidante relativa con respecto al ácido ascórbico (AAR) mostró que los extractos etanólicos de hojas, tallos y flores tienen una mayor actividad antioxidante por el método DPPH • Superior al patrón. A 250 ppm los extractos hojas (petrol), hojas y (diclorometano), tallos (petrol) y flores (diclorometano) presentaron $\%$ de inhibición del radical $\mathrm{DPPH} \bullet$ inferiores a $38,95 \%$ lo que nos indica que por esta técnica no es posible valorarlos. La evaluación de actividad antioxidante de extractos etanólicos de hojas, tallos y flores de Baccharis revoluta a través del método que utiliza el radical libre 1,1-difenil-2- picrilhidrazilo (DPPH•), presentó de manera significativa actividad antioxidante, con una $\mathrm{IC}_{50} \mathrm{y}$ actividad antioxidante relativa de $7,2 \%$ y $43.64 \%$, para el extracto etanólico de hojas, 6,95 y $45.57 \%$ para el extracto etanólico de tallos y 7,1\% y $44.16 \%$ para el extracto etanólico de flores, lo que nos determina una gran potencialidad de estos extractos.

\section{Agradecimientos}

A la Universidad El Bosque, por la financiación del proyecto código PCI 2012-347. Los autores manifestamos no tener conflicto de intereses

\section{Referencias}

1. Ariza Espinar L. Las especies de Baccharis (Compositae) de Argentina central. Boletin de la Academia Nacional de Ciencias, 1973; 50(1-4): 175-305.

2. Cuatrecasas José, Prima Flora Colombiana. COMPOSITAE ASTEREAE. Instituto Botánico de la Universitaria; 1969: 233-299.

3. Bremer K. Asteraceae: cladistics and classification. Portland, Oregon. Timber Press; 1994.

4. Cuatrecasas J. Miscellaneous notes on Neotropical Flora, XV. New taxa in the Astereae Phytologia, 1982; 52: 166-177.

5. Arriaga-Giner, F. J., E. Wollenweber, I. Schober, P. Dostal and S. Braunt, $2 \beta$-Hydroxyhautriwaic acid, a clerodane type diterpenoid and other terpenoids from three Baccharis species Phytochemystry. 1986; 25(3): 719-721.

6. Bohlmann Ferdinand, Banerjee Shanta, Jakupovic Jasmin, Grenz Michael, Misra Laxmi N., Schmeda-Hirschmann Guillermo, King Robert M. and Robinson Harold, Clerodane and labdane diterpenoids from Baccharis species Phytochemystry, 1985; 24(3): 511-515.

7. Bohlmann Ferdinand, Zdero Christa, King Robert M. and Robinson Harold, Kingidiol, a kolavane derivative from Baccharis kingii Phytochemystry, 1984; 23(7): 1511-1512.

8. Bohlmann,Ferdinand Scheidges Cornelius, Zdero Christa, King Robert M. and Robinson Harold, Ent-Labdanes from Baccharis Sternbergiana Phytochemystry, 1984; 23(5): 1109.

9. Bruce B. Jarvis, Norman B. Pena, S. Nilgün Cömezó lu and M. Madhusudana Rao, Non-trichothecenes from baccharis megapotamica Phytochemystry. 1986; 25(2): 533-535.

10. Faini Francesca, Rivera Patricio, Mahú Manuel and Castillo Mariano, Neo-clerodane diterpenoids and other constituents from Baccharis species Phytochemistry, 1987; 26(12): 3281-3283.

11. Gambaro Vicente, Chamy María C. and Garbarino Juan A. Neo-clerodane diterpenoids from Baccharis macraei, Phytochemystry, 1987; 26(2): 475-477.

12. Gambaro Vicente, Chamy María C., Garbarino Juan A., SanMartin Aurelio and Castillo Mariano, Neo-clerodane diterpenoids from Baccharis macraei, Phytochemystry, 1986: 25(9): 2175-2177.

13. Givovich Arturo, San-Martín Aurelio and Castillo Mariano, Neo-clerodane diterpenoids from Baccharis incarum Phytochemystry, 1986; 25(12): 2829-2831.

14. Thais Maira A. Biondo, Mirtes M. Tanae, Eliana Della Coletta, María Teresa R. Lima-Landman, Antonio J. Lapa, Caden 
Souccar June. Antisecretory actions of Baccharis trimera (Less.) DC aqueous extract and isolated compounds: Analysis of underlying mechanisms Journal of Ethnopharmacology, 2011; 136(2): 368-373.

15. Rodrígues Carmem R.F., Dias Jacqueline H., Semedo Juliane G., da Silva Juliana, Ferraz Alexandre B.F., Picada Jaqueline N., Mutagenic and genotoxic effects of Baccharis dracunculifolia (D.C.) Journal of Ethnopharmacology, 2009; 124(2): 321-324.

16. Da Cruz Pádua Bruno, Silva Lucas Dornela, Rossoni Joamyr Victor Júnior, Humberto Jorge Luiz, Martins Chaves Míriam, Silva Marcelo Eustáquio, Pedrosa Maria Lucia, Caldeira Costa Daniela, Antioxidant properties of Baccharis trimera in the neutrophils of Fisher rats Journal of Ethnopharmacology, 2010; 129(3): 285-420.

17. Xavier V.B., Vargas R.M.F., Cassel E., Lucas A.M., Santos M.A., Mondin C.A., Santarem E.R., Astarita L. Sartor V., T., Mathematical modeling for extraction of essential oil from Baccharis spp. by steam distillation Industrial Crops and Products, 2011; 33(3): 599-604.

18. Egly Feresin Gabriela, Tapia Alejandro, Gimenez Antonio, Gutierrez Ravelo Angel, Zacchino Susana, Sortino Maximiliano, Schmeda-Hirschmann Guillermo, Constituents of the Argentinian medicinal plant Baccharis grisebachii and their antimicrobial activity Journal of Ethnopharmacology, 2003; 89(1): 73-80.

19. Cannel R., J.P., Natural Products Isolation. Humana Press, 1998: 472.

20. Anderson, T. G. An evaluation antimicrobial susceptibility testing. In antimicrobial agents annal. New York, Plenum Press; 1961.

21. Barry, A. L. An improved single disk method for testing the antibiotic. Susceptibility of rapidly growing pathogens. Am. J. Clin. Pathol. 1970; 53: 149-158.

22. Brand-WIlliams, W.; Cuvelier, M. E. and Berset, C. Use of a Free Radical Method to Evaluate Antioxidant Activity. Lebens. Wiss. U.Technol., 1995; 28: 25-30.

23. Prior, R.L.; Wu, X. and Schaich, K. Standardized Methods for Determination of Antioxidant Capacity and Phenolics in Foods and Dietary Supplements. J. Agric. Food Chem. 2005; 53: 4290-4302.

24. Suja, K.P.; Jayalekshmy, A. and Arumughuan, C. Free Radical Scavenging Behaviour of Antioxidant Compounds of Sesame (Sesame indicum L.) in DPPH• System. J. Agric. Food Chem. 2004;52: 912-915.

25. Tapia Alejandro, Rodriguez Jaime, Theoduloz Cristina, Lopez Susana, Egly Feresin Gabriela, Schmeda-Hirschmann Guillermo, Free radical scavengers and antioxidants from Baccharis grisebachii Journal of Ethnopharmacology, 2004; 95(2): 155-161.

26. Villano, D.; Fernández-Pachón, M.S.; Moyá, M.L.; Troncoso, A.M. and García-Padilla, M.C. Radical Scavening Ability of Polyphenolic Compounds Towards DPPH Free Radical. Talanta, 2007; 71: 230.

27. Nausa, J. G. (2014). "Evaluación Clínica y radiográfica de injertos biocerámicos tipo Hidroxiapatita como alternativa en la reconstrucción de alveolos dentarios postexodoncia."
28. Galvez, Z. Y. A. and V. E. M. Burbano (2015). "Bacillus: género bacteriano que demuestra ser un importante solubilizador de fosfato.” NOVA Publicación en Ciencias Biomédicas.

29. Ramírez, L. C. C., et al. (2014). "Determinación de la presencia de bacterias patógenas para el humano en aguas de riego en la cuenca alta de la sabana de Bogotá; DC Colombia." Nova 12(22).

30. Corrales, L. C., et al. (2015). "Bacterias anaerobias: procesos que realizan y contribuyen a la sostenibilidad de la vida en el planeta." Nova 13(24): 55-82. 